\title{
Cooperação Internacional em ciência e Tecnologia: Refletindo Conceitos e Questões Contemporâneas*
}

\author{
Maria Clotilde Meirelles Ribeiro** e Amilcar
} Baiardi***

\section{Introdução}

0 conceito de "economia informacional” (CASTELLS, 1992) é de utilidade no presente texto. Em seu núcleo, a fonte fundamental de geração de riqueza está relacionada à habilidade de criar conhecimento novo e aplicá-lo à esfera produtiva por meio de procedimentos tecnológicos, organizacionais e do processamento da informação, o que leva o conhecimento científico e tecnológico a consti-

\footnotetext{
* Artigo recebido em 16 de outubro de 2012 e aceito para publicação em 6 de junho de 2014.

** Doutoranda em Administração junto ao programa da Escola de Administração da Universidade Federal da Bahia (UFBA), professora da Universidade Federal do Vale do São Francisco (Univasf), pesquisadora do Laboratório de Análise Política Mundial (Labmundo/UFBA) e membro da Rede de Cooperação Acadêmica para a Formação em Gestão Internacional (Labmundo). E-mail: clotilde.ribeiro.2008@hotmail.com.

*** Pós-doutor em História das Políticas de Ciência e Tecnologia no Institute and Museum of the History of Science (IMSS) (Florença, Itália), professor titular da Universidade Federal da Bahia (UFBA) e professor da Pós-graduação da Universidade Católica do Salvador (UCSal). E-mail: amilcarbaiardi@uol.com.br.
}

CONTEXTO INTERNACIONAL Rio de Janeiro, vol. 36, nº 2, julho/dezembro 2014, p. 585-621. 
tuir-se no elemento de diferenciação mais determinante entre os povos no contexto internacional contemporâneo.

Esta diferenciação, que segundo Landes (1994; 1998) dividiu o mundo entre saber e riqueza, de um lado, e ignorância e pobreza, do outro, se baseia na essência de um aforisma de Francis Bacon (1952, p. 107) em Novum organum, "conhecimento e poder humano são sinônimos", visto que o saber é inequívoca condição para a hegemonia, seja ela política ou econômica. Quando política, se expressa no poder militar e, quando econômica, se estabelece no poder de criar assimetrias de mercado, fazendo seus produtos valerem relativamente mais. Diante disso, pode-se concluir que não existe cooperação internacional em ciência e tecnologia (C\&T), completamente desinteressada em relação às consequências para a geopolítica e para o mercado externo, e que seja completamente aberta a ponto do conhecimento estratégico de um Estado-nação poder sofrer o processo de spillover effects, ou seja, derramamento de conhecimentos para outros Estados, na cooperação em C\&T.

Uma análise da cooperação internacional pode enfocar desde os aspectos conceituais, envolvendo esforços de sistematização, até os casos concretos, passando por fatores motivadores, interfaces, estratégias e articulações políticas, bem como instrumentos, resultados e sua consonância com as diretrizes políticas dos países envolvidos. Estas, por sua parte, isoladamente poderão ensejar o exame de condicionalidades, que serão corresponsáveis pelo grau de empoderamento dos receptores do conhecimento a ser produzido no processo. No caso em pauta, define-se como campo da abordagem o conceitual, com ênfase nos traços e fisionomias que a cooperação internacional em C\&T vem assumindo no Brasil, envolvendo inclusive o caso concreto da Empresa Brasileira de Pesquisa Agropecuária (Embrapa).

Considerando as transformações recentes na esfera das relações internacionais - que vêm redefinindo alianças, blocos e interesses de toda a 
natureza, econômicos, de macrogeopolítica e de poder militar-, como contemporaneamente se pode conceituar, classificar e entender a cooperação em C\&T, sobretudo aquela que diz respeito a um Estado-nação como o Brasil, que opera como doador e como receptor?

O texto busca dar resposta a esta pergunta-guia, inicialmente focalizando as bases conceituais e tipológicas da cooperação internacional em C\&T. Em continuação, lança um olhar sobre a mudança de enfoque ocorrida nas relações internacionais, sobretudo nas duas últimas décadas, e, por último, explora as particularidades e as controvérsias sobre as principais questões ligadas ao tema no mundo contemporâneo, bem como algumas especificidades no caso do Brasil.

\section{Cooperação Internacional: Uma Visão Conceitual}

Não há consenso na literatura quanto ao conceito de cooperação internacional. Num plano geral, cooperação corresponde a uma atividade conjunta para cujo resultado concorrem atores que se movem por interesses não predominantemente pecuniários, cada um concebendo-se como agente e não mero receptor da atividade.

A partir do final da Segunda Guerra Mundial, surge a "cooperação para o desenvolvimento" (CID), a qual, consoante Troyjo (2003), contempla os vetores da cooperação científico-tecnológica e da cooperação técnica. A inserção da dimensão C\&T no arcabouço da CID se deve ao fato de ser exatamente no pós-guerra que Schmookler (1966) relacionou C\&T, invenção e inovação com crescimento econômico. Os estudos sobre a CID têm merecido diferentes abordagens de autores, havendo distintas visões sobre a natureza e interesses postos entre doadores e receptores. Amorim (1994) lembra que tal cooperação tem como importante pressuposto a ideia da "alteridade", isto é, o respeito de um Estado pela existência autônoma do outro. 
Sanahuja e Galán (1999) e Ayllón (2006, p.7) argumentam que a CID consiste em "uma série de intervenções internacionais realizadas pelos atores públicos e privados, para promover o progresso econômico e social dos países em vias de desenvolvimento (PVDs) e conseguir um progresso mais justo e equilibrado no mundo, com o objetivo de construir um planeta mais seguro e pacífico". Voltado para metas comuns fundamentadas em critérios de solidariedade, equidade, eficácia, interesse mútuo, sustentabilidade e corresponsabilidade, o Sistema de Cooperação Internacional para o Desenvolvimento (SCID) configura-se como uma ampla rede de organizações de diversas naturezas, entre elas organismos internacionais, como o Fundo Monetário Internacional e o Banco Mundial, governos, instituições públicas, organizações não governamentais (ONGs), empresas e outras entidades da sociedade civil que planejam e executam ações de cooperação no âmbito internacional, o que inclui uma extensa rede multilateral de financiamento e cooperação ao desenvolvimento. O SCID engloba estratégias, recursos e ações lastreadas nos princípios e regras dos vários ramos do Direito Internacional, do Direito ao Desenvolvimento e dos Direitos Humanos.

Neste sentido, a finalidade primordial da CID deve ser a erradicação da pobreza, do desemprego e da exclusão social, bem como o aumento dos níveis de desenvolvimento político, social, econômico e cultural nos PVDs, alguns destes hoje reconceituados quanto ao estágio e atuando também como doadores na arena internacional, como é o caso do Brasil. A CID situa-se no campo mais amplo das relações internacionais, e é neste âmbito que se explica o seu nascimento e estruturação no quadro da Guerra Fria e do processo de descolonização.

O termo não tem validade para todo tempo e lugar, pois como conceito sofre mudanças, em função dos acontecimentos históricos, do pensamento, das políticas e objetivos das relações Norte-Sul. No vocabulário das relações internacionais, primeiro emergiram os termos ajuda e assistência técnica. Consoante Soares (1994), o Dictionnaire 
de la terminologie du Droit International, publicado nos anos 1960, aponta como significado do verbete "Assistance technique": 1

Expressão que designa a ajuda fornecida, sob a égide da ONU, pelos Estados com estrutura econômica adiantada aos países insuficientemente desenvolvidos, a fim de colocar à disposição destes os meios técnicos que lhes fazem falta para promover suas economias. A assistência técnica consiste em uma ajuda variada e em princípio gratuita, repartida pelos mecanismos internacionais em proveito dos Estados subdesenvolvidos (REUTER, 1955, p. 100).

Muitos autores, como Soares (1994), Lafer (1994) e Amorim (1994), destacam que tal terminologia e enfoque decorrentes são inadequados nos dias atuais, em função de profunda mudança de abordagem nas relações internacionais. Os Estados já não são mais tratados como subdesenvolvidos ou de industrialização tardia, e sim como países em via de desenvolvimento, caracterizando um processo em andamento. Ademais, a noção de assistência ligada à de ajuda, denotando uma concepção de perpetuação da dependência, já não é mais cabível contemporaneamente. Assim, os conceitos de ajuda e de assistência técnica foram sendo substituídos pelo de cooperação técnica, e, mais recentemente, pelo de transferência de tecnologia (este também usado em contratos que envolvem propriedade intelectual), mudança que é constatada na evolução dos termos dos acordos de cooperação. No foco da tipologia da CID, Ayllón (2006) aponta seus instrumentos e finalidades, sendo a cooperação em C\&T um deles.

\section{O Termo Ciência e sua Acepção ao Longo dos Tempos}

Etimologicamente, o termo deriva do latim scientia e remete a "saber" ou a "conhecimento", não indicando que todo saber seria cientí- 
Maria Clotilde Meirelles Ribeiro e

Amilcar Baiardi

\section{Quadro 1}

Instrumentos e Finalidades da Cooperação Internacional ao

Desenvolvimento

\begin{tabular}{|l|l|}
\hline \multicolumn{1}{|c|}{ Tipo } & \multicolumn{1}{|c|}{ Finalidade } \\
\hline Cooperação econômica & $\begin{array}{l}\text { Fortalecimento do setor produtivo, infraestrutura } \\
\text { institucional, desenvolvimento de serviços. }\end{array}$ \\
\hline Cooperação em C\&T & $\begin{array}{l}\text { Transferência e intercâmbio de tecnologias aplicadas a } \\
\text { serviços básicos de educação, saúde, saneamento e } \\
\text { pesquisas. }\end{array}$ \\
\hline Ajuda financeira & $\begin{array}{l}\text { Facilitações de acesso a capitais, investimento produtivo, } \\
\text { linhas de crédito preferencial para importação, troca, } \\
\text { recompra, ou perdão da dívida externa. }\end{array}$ \\
\hline Assistência técnica & $\begin{array}{l}\text { Fortalecimento das habilidades e capacidades técnicas } \\
\text { presentes nos países do sul, intercâmbio de experiências e } \\
\text { conhecimento entre países. }\end{array}$ \\
\hline Ajuda humanitária & $\begin{array}{l}\text { Ajuda militar, socorro, proteção de direitos humanos, } \\
\text { acompanhamento de vítimas, pressão humanitária, } \\
\text { prevenção e mitigação de desastres naturais, epidemias etc. }\end{array}$ \\
\hline
\end{tabular}

Fonte: Adaptado de Ayllón (2006).

fico segundo Hessen (2000). Bazzo et al. (2003) lembram que na concepção tradicional a ciência seria um "empreendimento autônomo, objetivo, neutro e baseado na aplicação de um código de racionalidade alheio a qualquer tipo de interferência externa", que teria no método científico a ferramenta intelectual responsável por seus produtos. Contemporaneamente, a partir da clássica obra de Robert King Merton (2008), praticamente se estabeleceu consenso de que a produção científica teria inúmeras determinantes, inclusive sociais e políticas. O prestígio alcançado pela obra The Scientific Life de Shapin (2008), com grande inspiração em Merton, confirma essa ampla aceitação de que a ciência sofre multideterminações.

A partir dessas contribuições, o desenvolvimento científico deixou de ser um processo regulado por rígido código de racionalidade, autônomo em relação a condicionantes externos sociais, políticos e psicológicos. Desta forma, o empirismo clássico que, segundo Popper (2000), gestou o método científico de índole fortemente positivista, 
com raízes, entre outros, em Francis Bacon (1952) e John Stuart Mill (1978), deixou de ser visto como dogma. A história da ciência mostra que muitas ideias científicas surgem por múltiplas causas, incluindo inspiração, condicionamentos socioeconômicos, ou até mesmo sorte ou serendipity, ${ }^{2}$ sem que necessariamente seja seguido um procedimento regulamentado como estabelecia o positivismo.

Ao longo do século XX, muitos esforços foram envidados para conferir à ciência uma definitiva conceituação. Apesar das diferenças, compartilham um núcleo comum, qual seja, identificá-la como uma atividade tipicamente humana de busca sistemática do conhecimento da natureza e dos seus fenômenos, inclusive o comportamento do homem, e que, em geral, tem início com a observação, seguindo-se a descrição, a experimentação e a teorização. Dependendo do tipo de objeto que se pesquisa, a experimentação, que é a tentativa de reproduzir em laboratório, de modo controlado, os fenômenos, poderá não existir, sendo substituída por um modelo teórico explicativo dos fenômenos naturais ou sociais (VIEIRA et al., 2010). Este conceito destoa do Positivismo Lógico, que entende o conhecimento científico como o produzido com o método considerado único, ideia fortemente desconstruída por Feyerabend (1989) e por Thuillier (1994).

A reação antipositivista daí decorrente se fundamenta em críticas de outros autores, entre eles Popper (2000) e Thomas Kuhn (2010). Este último foi influenciado por Merton (2008), que aponta problemas para manter os pressupostos racionalistas tradicionais. Com esses autores, a filosofia da ciência toma consciência da importância da dimensão social e do enraizamento histórico da ciência. Kuhn (2010) enceta um estilo interdisciplinar, na esteira do qual as fronteiras entre especialidades acadêmicas tendem a ser diluídas. Por sua vez, Bruno Latour (1997), no âmbito dos estudos sociais da ciência, entende a atividade científica como "um processo social, regulado por fatores não epistêmicos que teriam relação com pressões econômicas, ex- 
pectativas profissionais ou interesses sociais específicos" (BAZZO et al., 2003, p. 18).

\section{Conceituando Tecnologia}

Parece consenso entre antropólogos que a sociabilidade, a capacidade linguística e as habilidades técnicas foram fundamentais no processo de hominização, sobretudo na transição da condição de nômade, na qual o Homo sapiens sapiens se afirma, para a de fixado no território, após a primeira revolução agrícola (ALBERGONI, 1995; FABIETTI, 1995; GODELIER, 1995; PIGGOTT, [s.d.]).

As condições físicas limitadas da anatomia humana, em decorrência do processo evolutivo do cérebro e da perda de força física e de componentes corporais dilacerantes, como garras e presas, fizeram o homem recorrer às referidas habilidades na construção de artefatos para incrementar a capacidade de caçar, de modificar materiais e de construir instrumentos e armas inicialmente rudimentares, essenciais à evolução cultural.

Neste estágio, com início centenas de milhares de anos atrás, quando o Homo sapiens sapiens começa sua aventura na Terra, o conhecimento técnico era o único que embasava a evolução das civilizações. A gênese da ciência teria se dado durante a Antiguidade clássica, para alguns historiadores, ou durante a Revolução Científica pós-Renascimento. O primeiro encontro com reciprocidade entre essas duas entidades aconteceu no período helênico. Durante a Idade Média, houve uma descontinuidade, e a cooperação estreita somente se consolida a partir da Revolução Científica (BAIARDI, 1997).

Para Soares (1994), a tecnologia, definida como estudo das técnicas, inclusive de sua evolução, é a busca do conhecimento de como produzir e desenvolver artefatos, que constituem um conjunto dos bens corpóreos e incorpóreos. Ao longo da história, a partir de vantagens 
culturais e econômicas, um grupo de países demonstrou mais habilidades em acumular condições favoráveis à potenciação dos fatores de produção e, sobretudo, de reprodução e inovação dos próprios bens tecnológicos. Vis-à-vis outros territórios, neles emergiram em maior grau agentes econômicos com maior propensão a assumir riscos e a investir produtivamente. Isto fez com que os mesmos fossem pioneiros na geração de inovações, o que estabeleceu a diferenciação fundamental entre países mais e menos industrializados (LANDES, 1994; 1998).

A definição contemporaneamente mais aceita para tecnologia é aquela utilizada pela corrente que no campo da economia da inovação é denominada de neo-schumpeteriana ou evolucionista, cuja notoriedade se dá a partir de 1989 com o lançamento da obra Technical Change and Economic Theory. Nesta comunidade, vide Dosi et al. (1990), Stokes (2005) e Rosenberg (2006), tecnologia seria um “conjunto de conhecimentos, eventualmente derivados de conhecimento científico, que se aplicam a determinado ramo de atividade" ou a "conjunto dos processos especiais relativos a uma determinada arte ou indústria". Para esses autores, a dimensão da aplicação está presente na tecnologia, o que não ocorre com a ciência. A interdependência entre ciência e tecnologia se acentuou a tal ponto que não se discute o acrônico C\&T, muitas vezes acrescido de I (C\&T\&I), o que sugere que a tecnologia comporta, além da dimensão aplicativa, a dimensão mercadológica.

Não obstante esta interdependência, autores como Rosenberg (2006) chamam atenção para a riqueza das cadeias causais entre a ciência e a vida econômica e social e desta para a tecnologia, e outros, a exemplo de Stokes (2005), afirmam que o modelo linear que articula ciência com mercado (Pesquisa básica $\rightarrow$ Pesquisa aplicada $\rightarrow$ Desenvolvimento $\rightarrow$ Produção e operações) está longe de ser o único e o mais adaptado à realidade das relações causais. 
Bazzo et al. (2003) apontam que há autores para os quais a relação ciência-tecnologia é que diferencia a técnica da tecnologia, levando à conceituação da tecnologia como ciência aplicada. O termo "técnica" faria referência a procedimentos, habilidades, artefatos e desenvolvimentos sem ajuda do conhecimento científico, enquanto "tecnologia" referir-se-ia aos sistemas desenvolvidos a partir do conhecimento científico. Entretanto, a tese da dependência absoluta da tecnologia em relação à ciência tem sido amplamente contestada, inclusive pelos neo-schumpeterianos, sendo hoje difícil de defendê-la.

Contemporaneamente, as evidências informam que uma investigação científica independente de possíveis aplicações, ou seja, sem nenhum horizonte de vir a colaborar com a tecnologia, não corresponde aos tipos de projetos de pesquisa a serem financiados sem restrições (DELORS, 1994). Isso porque os componentes científicos teóricos e tecnológicos práticos são indissociáveis do contexto social, e subjacente a esta constatação está o caráter da tecnologia como sistema, que denota a sua condição de não autonomia, com intercâmbio dos aspectos técnicos e aqueles da sua administração.

Assim, diante da importância do componente tecnológico nas inovações de produtos e processos, fica clara a exigência de rigorosa prioridade nos investimentos em pesquisa e desenvolvimento (P\&D) para que certos países se mantenham engajados à competição mundial, sobretudo aqueles que baseavam sua competitividade na baixa remuneração da força de trabalho, que deixou de constituir vantagem comparativa perante a automação.

Troyjo (2003) salienta que a trajetória de desenvolvimento desde a última metade do século XX se deu à margem do próprio sistema internacional, resultando muito mais de inovações tecnológicas geradas por estruturas de $\mathrm{P} \& \mathrm{D}$ e sua transposição para o domínio do comércio internacional do que por decisões concertadas em fóruns multilaterais. Essa realidade tem grande implicação para os países 
emergentes que ainda fundamentam a competitividade, em parte, na baixa remuneração da força de trabalho, na inflação, no protecionismo exagerado e nas barreiras não alfandegárias. Como este bloco de países é desigual na capacidade de realizar P\&D e nos indicadores de competitividade, conviria que a identidade em outros aspectos, e que gerou o fórum internacional denominado BRICS, fosse facilitadora da cooperação internacional entre eles. Esta cooperação não seria assimétrica em todos os casos, visto que China, Rússia, Índia e África do Sul têm alguns setores competitivos. Neste conjunto, o Brasil assumiria liderança inequívoca na $\mathrm{P} \& \mathrm{D}$ voltada para a produção vegetal e animal.

Nesta etapa de desenvolvimento do capitalismo - a) quando as grandes corporações internacionais adquirem poderes só antes tidos pelo Estado, b) quando a questão nacional já não é relevante nos investimentos em P\&D, visto que uma corporação aloca recursos, pesquisadores e facilities, onde há massa crítica para gerar inovações e não mais prioritariamente em sua home base, e c) no momento no qual se generaliza à escala mundial a prática de terceirizar $\mathrm{a} \& \mathrm{D}, R \& D$ outsourcing, que se tornou comum tendo a Índia como prestadora de serviços -, há que se repensar os termos da cooperação internacional em C\&T, uma vez que esta realidade pode estabelecer novos caminhos e atalhos para as antigas vias (BAIARDI; BASTO, 2013).

\section{A Cooperação Internacional no Eixo da Ciência e Tecnologia}

Como já lembrado, ciência e tecnologia não nascem juntas. A ciência tem gênese nos antigos conselhos de sábios, que agrupavam filósofos, sacerdotes, magos e escribas; e a tecnologia, enquanto área do saber relacionado ao aprimoramento de artefatos que visavam conferir precisão às observações da natureza, aparece centenas de milênios de anos após o homem ter descoberto a técnica. Durante o período 
helênico, a relação entre ciência e tecnologia se acentuou e teve como evidência experimentos de termodinâmica e hidráulica na Escola de Alexandria. A Idade Média, com sua prevalência do paradigma escolástico, não foi pródiga nesta relação, provocando uma descontinuidade, embora se registre a descoberta e o desenvolvimento de inúmeros artefatos, sobretudo visando poupar força de trabalho, bem como a experiência das guildas medievais, que eram, ao mesmo tempo, uma escola de aprendizado tecnológico e reduto de cooperação internacional de saber (EPSTEIN; PRAK, 2009).

O Renascimento como precursor da Revolução Científica fomentou esta relação, e os exemplos de lunetas, barômetros, termômetros etc. evidenciam que estes conhecimentos de ciência e tecnologia passariam a caminhar juntos para sempre, o que foi facilitado pela descoberta do tipo móvel, que revolucionou a imprensa, permitindo o ensino de técnicas. Este ensino deixava de se dar homem a homem nas oficinas e guildas (BAIARDI, 1997; VIEIRA et al., 2010). O exponencial crescimento dos estudos e da produção de conhecimento neste campo nas últimas décadas é justificado pela relevância que as questões relativas à ciência e à tecnologia possuem na definição das condições da vida humana.

A relação das sociedades com o que se denomina tecnociência, tecnologias fortemente dependentes do progresso científico, lastreia um dos critérios de classificação de sociedades. Para Ortega y Gasset (2005), a sociedade atual caracteriza-se pelo caráter de imprescindibilidade que a técnica nela ocupa e da consciência que o homem adquire sobre isso. Nesta linha, Bazzo et al. (2003) ressaltam que a ciência e a tecnologia influenciam as formações sociais, o que é reforçado pelo fato da C\&T vir crescentemente invadindo a agenda internacional, o que também é justificado pela sua ampla transversalidade.

Troyjo (2003) distingue três tipos de cooperação - científico-tecnológica, técnica e educacional - e delimita suas especificidades (Quadro 2). 
Cooperação Internacional em Ciência e

Tecnologia: Refletindo Conceitos...

\section{Quadro 2}

Especificidades da Cooperação Internacional

\begin{tabular}{|l|l|l|}
\hline \multicolumn{1}{|c|}{ Científico-Tecnológica } & \multicolumn{1}{|c|}{ Técnica } & \multicolumn{1}{c|}{ Educacional } \\
\hline $\begin{array}{l}\text { Propagação vertical de } \\
\text { conhecimentos }\end{array}$ & $\begin{array}{l}\text { Propagação horizontal de } \\
\text { conhecimentos }\end{array}$ & $\begin{array}{l}\text { Intercâmbio intelectual } \\
\text { (discentes e docentes) }\end{array}$ \\
\hline $\begin{array}{l}\text { Inovação de processos e } \\
\text { produtos }\end{array}$ & $\begin{array}{l}\text { Definição da tendência por } \\
\text { parte do transmissor e } \\
\text { financiamento realizado } \\
\text { majoritariamente por este }\end{array}$ & $\begin{array}{l}\text { Formação de recursos } \\
\text { humanos }\end{array}$ \\
\hline $\begin{array}{l}\text { Cofinanciamento e } \\
\text { elaboração conjunta de } \\
\text { atividades }\end{array}$ & $\begin{array}{l}\text { Adesão a programas e/ou } \\
\text { áreas previamente } \\
\text { definidos pelo transmissor }\end{array}$ & $\begin{array}{l}\text { Maio universitário e } \\
\text { cooperação científica }\end{array}$ \\
\hline $\begin{array}{l}\text { Apoio ou fomento de } \\
\text { instituições de excelência }\end{array}$ & $\begin{array}{l}\text { "Excelência" não é } \\
\text { precondição para todos os } \\
\text { parceiros }\end{array}$ & Bolsas de estudo \\
\hline $\begin{array}{l}\text { Países e/ou instituições de } \\
\text { elevado desenvolvimento } \\
\text { tecnológico setorial }\end{array}$ & $\begin{array}{l}\text { Tendência a programas } \\
\text { direcionados a problemas } \\
\text { de base social (basic roots) }\end{array}$ & $\begin{array}{l}\text { Escolas técnicas, formação } \\
\text { de pessoal qualificado }\end{array}$ \\
\hline
\end{tabular}

Fonte: Elaboração da autora com base em Troyjo (2003).

Na cooperação em C\&T, o autor supõe equivalência de competência técnica e científica dos cooperantes e um objetivo que vai além da transferência de conhecimentos, compreendendo inovação para o desenvolvimento econômico. O montante de conhecimento é alterado significativamente ao longo do processo, e admite-se que a ação conjunta dos parceiros trará resultados que não seriam facilmente obtidos na pesquisa isolada. Há ainda equivalência entre as motivações da cooperação e os objetos político-diplomáticos de amplo alcance.

A cooperação técnica, para ele, possui caráter assistencialista e "marca um processo de simples transferência de saberes, conhecimentos, equipamentos, recursos humanos etc. colocados à disposição de um agente de menor desenvolvimento relativo, permitindo saltos na busca da capacitação" (TROYJO, 2003, p. 108). Em termos ideais, visa o nivelamento da qualidade da pesquisa e produção internacional 
numa área específica, não necessariamente aumentando o estoque de conhecimentos, pois não há a preocupação em inovar. A cooperação educacional seria um caso particular da cooperação técnica, atuando sobretudo por meio de intercâmbio e de bolsas de estudo.

Uma peculiaridade de magnitude para a qual Troyjo (2003) chama a atenção, no caso de uma atividade de cooperação cuja matéria-prima e produto essencial é o conhecimento, é que, não obstante os objetivos serem definidos conjuntamente, o que se busca, malgrado os protocolos do acordo, é passível de interpretações e apropriações distintas, e, portanto, de ganhos científico-tecnológicos, políticos, econômicos e sociais diferentes pelos países cooperantes. Ademais, as atividades de cooperação envolvem conhecimentos que, a princípio, não poderiam ser apreendidos apenas pelas modalidades tradicionais de comércio internacional. $O$ autor acrescenta que a cooperação científico-tecnológica antes da Guerra Fria se fincava nas modalidades tradicionais de intercâmbio de professores, estudos conjuntos e participação em eventos científicos, período em que o seu componente tecnológico não era ainda plenamente reconhecido como um fator decisivo para aumento da produtividade. Já a cooperação técnica objetivava, na sua concepção mais pura, alavancar o desenvolvimento social e econômico do país "receptor", definida como um mecanismo paralelo às relações estritamente econômicas ou comerciais entre países desenvolvidos e em desenvolvimento. Troyjo (2003) sublinha que os mecanismos que decorrem desses conceitos em voga nas décadas de 1960-70 estão hoje superados, e novas modalidades de cooperação técnica tendem a surgir.

Soares (1994) esclarece que o conceito de assistência técnica internacional se concentra nos movimentos de cooperação verificados desde o estabelecimento e o reconhecimento das desigualdades entre nações, o que inclui envio de peritos, outorga de bolsas de estudo, estágios, seminários de formação e criação de instituições-piloto. O autor argumenta que a cooperação técnica internacional hoje não é alvo 
de entendimento universal, e que a inadequação da terminologia "assistência técnica" aos dias atuais se deve não só à mera questão vocabular, mas a uma mudança de enfoque nas relações internacionais. Isso não estaria ligado a questões humanitárias ou de legitimação de ações unilaterais dos países industrializados nos PVDs, mas sim à afirmação de um direito ao desenvolvimento desses Estados, aliado ao dever de cooperação por parte dos países industrializados, dentro dos princípios da Carta da ONU. Ressalta que, embora a denominação do fenômeno de transferência de recursos entre países, tanto na sua forma bilateral, quanto multilateral, tenha recebido a expressão cooperação técnica internacional, as expressões "auxílio", "ajuda" e "assistência técnica" não desapareceram, expressando, sobretudo, a modalidade de formação de técnicos, quadros administrativos e gestores dos PVDs, pelos países industrializados ou com maior desenvolvimento relativo.

No foco dos critérios que permitem classificar as modalidades de cooperação técnica internacional, Soares (1994) identifica três tipos: a) a origem dos recursos dos remetentes, podendo ser pública ou privada, com desdobramentos; b) a natureza das relações estabelecidas entre os Estados participantes, gerando a cooperação multilateral e a bilateral; e c) o objetivo que a cooperação tem em vista, podendo assumir duas modalidades: c.1) transmissão de conhecimentos nas formas de assistência técnica e de transferência de tecnologia; e c.2) transferência de capitais, nas formas de transferência via organismos do sistema ONU ou através de organizações regionais; ou ainda as formas de transferência direta dos Estados remetentes, e aquelas com atuação dos bancos privados, isoladamente ou consorciados.

Em outra direção, Baiardi e Ribeiro (2011, p. 596) analisam motivos para a transferência de saberes e competências na esfera da C\&T internacional, destacando:

i) criar ou ampliar uma vantagem competitiva do território na esfera econômica, militar, es- 
portiva, cultural etc.; ii) compartilhar recursos e possibilidades decorrentes da dotação de recursos naturais ou criados por meio de intervenções tipo infraestrutura,obras de engenharia etc.; iii) criar um ambiente inovativo para favorecimento de empresas; iv) enfrentar ameaças, de desastres naturais, enfermidades, agressão; v) como veículo de difusão de conhecimento; vi) para a construção dos sistemas nacionais e regionais de inovação; vii) visando fomentar a divisão do trabalho de pesquisa básica ou aplicada; viii), visando formação de redes ou grupos de pesquisa para fortalecimento de competências em determinadas áreas etc.

\section{Breve Panorama Histórico}

$\mathrm{O}$ atual sistema das relações internacionais estabelecido ao final da Segunda Guerra Mundial e consubstanciado no sistema da segurança coletiva sob a égide da Organização das Nações Unidas (ONU) tem marcada diferença em relação ao sistema vigente no entreguerras, com a Liga das Nações, e diferença ainda mais marcante comparativamente aos sistemas de séculos anteriores. Se nestes a preocupação era estabelecer regras negativas nas relações internacionais (ou seja, regras que assegurassem a paz através de normas proibitivas de ações perturbadoras), a partir do sistema da ONU a ênfase recai no estabelecimento de regras de construção de comportamentos que incentivem a cooperação (SOARES, 1994).

No século XX, identificam-se três momentos da cooperação internacional. Nos primórdios do século, ela obedeceu às aspirações universalistas dos cientistas do século XIX, e a atividade científica era vista como de domínio e exercício universais, não obstante esse universalismo fosse constrangido por interesses nacionais. A ideia de ciência se prestava pouco a uma interpretação econômica, consoante Troyjo (2003), e mais à biologia, física, química, matemática, astronomia e 
geologia. Assim, a cooperação de antes das Grandes Guerras é caracterizada por um intercâmbio interinstitucional, e os governos participam dessas atividades de maneira acessória.

Já no período que vai da Primeira Guerra Mundial até a Guerra Fria, a cooperação internacional passa a buscar conhecimentos voltados para objetivos geopolítico-militares e a noção de comunidade de cientistas é substituída pela ideia de alianças geopolíticas que se utilizam da C\&T como instrumento de aproximação. Permanecia a prevalência dos fatores político-ideológicos e imaginava-se que as descobertas científico-tecnológicas poderiam ser tanto ameaças como auxílios ao desenvolvimento e à segurança dos países. Mais que no século XIX, aqui houve presença de pesquisadores de países colonizadores nas suas respectivas colônias, o que levou a algum desenvolvimento científico. Contudo, neste caso não se pode falar de cooperação internacional, visto que o território colonizado poderia até ser uma nação, mas não era um Estado-nação, consoante Gaillard (1994).

Contemporaneamente, com a emergência de uma ordem internacional em que prevalecem fatores econômico-comerciais, essa mesma perspectiva vem a reger a cooperação internacional, implicando que os atores da C\&T, sobretudo centros de pesquisa e empresas, não mais podem permanecer isolados. Para o Brasil, isso representa significativa mudança, pois, desde os primórdios da República até a consolidação da atividade científica no Brasil nos anos 1950, a atenção era voltada preponderantemente para a ciência básica.

Sob outro prisma de análise, enfocando os planos bi e multilateral de cooperação nos momentos demarcados pela Guerra Fria, verifica-se que as atividades no período bipolar se desenvolviam distintamente do atual sistema de polaridades indefinidas, como sintetiza o Quadro 3. 
Maria Clotilde Meirelles Ribeiro e

Amilcar Baiardi

\section{Quadro 3}

Cooperação Internacional Antes Versus Pós-Guerra Fria

\begin{tabular}{|l|l|}
\multicolumn{1}{c|}{ uerra Fria } & \multicolumn{1}{c|}{ Pós- uerra Fria } \\
\hline $\begin{array}{l}\text { Prevalência de "intercâmbio" sobre } \\
\text { cooperação }\end{array}$ & $\begin{array}{l}\text { Prevalência de cooperação sobre } \\
\text { "intercâmbio" }\end{array}$ \\
\hline $\begin{array}{l}\text { Prevalência de Estado sobre sociedade } \\
\text { civil }\end{array}$ & $\begin{array}{l}\text { Prevalência de sociedade civil sobre } \\
\text { Estado }\end{array}$ \\
\hline Prevalência de "ação" sobre "cooperação" & Convivência entre "ação" e "cooperação" \\
\hline Atividades politicamente orientadas & Atividades economicamente orientadas \\
\hline rientação ideológica & Desorientação ideológica \\
\hline bjetivo é aliança geopolítica & bjetivo é a conquista de mercados \\
\hline
\end{tabular}

Fonte: Elaboração da autora com base em Troyjo (2003).

Essas diferenças evidenciadas no plano temporal, nitidamente marcado por um primeiro momento de orientação político-ideológica que sobrepuja aquela de caráter econômico-comercial que vem a se tornar hegemônica no pós-Guerra Fria, refletem-se na realidade brasileira em seu relacionamento externo. Nesses dois momentos, constatam-se claras reorientações político-estratégicas dos governos. Com os EUA, enquanto nos anos 1950 o relacionamento era mais voltado ao treinamento de pessoal técnico, no Brasil e no exterior, para operar máquinas e equipamentos manufaturados nos EUA e adquiridos pelo comércio bilateral, nos anos 1990 a cooperação passa a priorizar o eixo das novas tecnologias, a exemplo da conexão de redes de comunicação eletrônica. Já no plano Sul-Sul, se antes o Brasil buscava simplesmente prestígio político que lhe garantisse liderança no mundo em desenvolvimento, nos anos 1990 o relacionamento passa a se orientar no sentido de uma "presença brasileira no entorno do epicentro político-econômico sul-africano, marcando o renascimento econômico da África Austral" (TROYJO, 2003, p. 95).

No plano multilateral, o panorama mostra que, se antes os mecanismos disponibilizados pelo Programa das Nações Unidas para o Desenvolvimento (PNUD) permitiam aos PVDs o uso de recursos para fins assistencialistas, nos anos 1990 esses mecanismos são progres- 
sivamente substituídos por estruturas, a exemplo dos Grupos de Trabalho sobre Tecnologia de Informação (TI) da Comissão da ONU sobre C\&T para o Desenvolvimento, que, em conjunto com o Programa Information for Development (InfoDev) do Banco Mundial, passam a conformar de maneira preponderante o tratamento multilateral dado às TIs.

Um estudo realizado por Cervo (1994) na década de 1990 analisa a cooperação multilateral do PNUD com o Brasil e a cooperação bilateral recebida pelo país no período de 1960-90. Os resultados mostram uma superioridade da cooperação do PNUD, notadamente em função do planejamento estratégico, da flexibilidade e vinculação de seus programas aos órgãos da ONU, da universalidade de sua atuação e de certa mentalidade ideológica e política. O autor salienta que os programas do PNUD contribuíram para consolidar no Brasil alguns centros importantes de pesquisa, entre eles a Embrapa, o Instituto Brasileiro de Desenvolvimento Florestal (IBDF) e o sistema nacional de controle de qualidade de drogas e medicamentos, então responsabilidade do Instituto Adolfo Lutz da Fundação Oswaldo Cruz (Fiocruz).

Com base nos 401 projetos de cooperação técnica recebida até 1990, aprovados pelo PNUD e pelos governos estrangeiros envolvidos, Cervo (1994) conclui a existência de quatro subáreas de atuação desta cooperação no Brasil no período: i) Agrícola, focalizando tecnologias de alimentos, irrigação, florestas, pecuária, laticínios, fruticultura, pesca e controle de pragas; ii) Industrial, focalizando telecomunicações, energia elétrica, metalurgia, aplicações nucleares e siderurgia; iii) Engenharias nos seus vários ramos; e iv) Objetos diversificados (P\&D, treinamento, planejamento, tecnologias, ensino, desenvolvimento regional e meio ambiente).

Já os projetos de cooperação técnica bilateral recebida pelo Brasil nos anos 1970 e 1980 se pulverizavam em subáreas de atuação, deno- 
tando fraqueza na elaboração de programas conjuntos que priorizassem o desenvolvimento nacional. Em geral, eram pequenos projetos que intercambiavam peritos e treinandos ou assessorias a agências brasileiras. Não obstante, verifica-se uma orientação mais robusta por parte da Itália, no transporte ferroviário, do Japão na pesquisa agrícola, da França na cooperação científica universitária e da Alemanha em áreas tecnológicas avançadas (CERVO, 1994).

Na contemporaneidade, Troyjo (2003) aponta que, no Brasil, a cooperação internacional (sobretudo no eixo de C\&T) passou a comportar o diálogo com instituições de pesquisa e formuladores de política, distribuídos nos diversos ministérios, secretarias estaduais de C\&Te instituições, a exemplo da Fiocruz, Instituto de Tecnologia de Alimentos do Estado de São Paulo (ITAL), Câmaras de Indústria e Comércio, entre outros. De fato, o reconhecimento de que o investimento em $\mathrm{P} \& \mathrm{D}$ se tornou fundamental para a competitividade econômica e aumento do bem-estar social amplia o diálogo na área e leva municípios, estados da Federação e sociedade civil a se constituírem como interlocutores qualificados, voltados à cooperação internacional em C\&T. A realidade de quase todos os estados e muitos municípios no Brasil terem criado secretarias de ciência e tecnologia, e dentro delas uma estrutura dedicada à cooperação internacional, é emblemática desta mudança. (BAIARDI, 2004; RIBEIRO, 2009). Porém, a introdução de condicionalidades e de tematização da cooperação (com programas que privilegiam aspectos étnicos, culturais e de gênero, ao invés da capacidade concorrencial dos países emergentes), contribui para a erosão das atividades tradicionais de cooperação. Assim, a sociedade civil, inclusive a comunidade científica organizada, não espera mais o governo para promover cooperação, e prolifera acordos de caráter "interinstitucional”, à margem dos acordos intergovernamentais, ou seja, sem validade jurídica pelo Direito Internacional Público, quadro que hoje leva a repensar uma nova interlocução necessária entre Estado e sociedade civil e entre o país e a cooperação internacional. 


\section{Cooperação Internacional em Ciência e Tecnologia: Refletindo Conceitos... \\ Questões Cruciais da Cooperação Internacional em C\&T Hoje}

Uma dificuldade para a concretização da cooperação internacional reside no aprofundamento do diálogo entre nações de culturas distintas, respeitando-se suas identidades e visões diversas acerca do desenvolvimento. As relações estabelecidas podem impor concessionalidades que venham a levar à dependência do país receptor, podendo definir também imposições condicionais. Ademais, as dificuldades com as restrições de recursos para a cooperação internacional vêm sendo cada vez maiores.

Outro desafio se encontra nos problemas jurídicos e políticos que permeiam a transferência internacional de tecnologia, frente aos quais Soares (1994) lembra que o campo da propriedade intelectual é um dos mais polêmicos e problemáticos que a cooperação técnica internacional enfrenta hoje. O campo engloba tanto a propriedade industrial (patentes, marcas de indústria, de comércio e de serviço e expressões ou sinais de propaganda), conforme a regulamentação brasileira pela Lei de Propriedade Industrial 9279, de 1996, quanto os novos aspectos dos direitos de autor (e, em particular, a regulamentação jurídica do software). O conceito de "transferência", pela natureza dos fenômenos envolvidos, envolve saber até que ponto a "transferência" significaria assimilação e capacidade de reprodução dos insumos ou produtos pela força própria dos PVDs. Tal preocupação decorre do fato de que tanto a produção original da tecnologia quanto a manutenção dos processos nela baseados são condicionadas a todo um conjunto que inclui um parque industrial de base, centros de pesquisa básica e aplicada e, sobretudo, mentalidades organizacionais, atributos estes com dotações variáveis nos PVDs. Assim, até que ponto uma tecnologia transferida indireta ou diretamente para um PVD significaria real aporte ao seu desenvolvimento ou simples processo de introdução de um bem, cuja manutenção exigiria continui- 
dade de assistência técnica pelos países industrializados, levando a perpetuar uma relação de dependências por parte dos PVDs? Ainda que se consiga estabelecer uma política de transferência de tecnologias apropriadas ao nível do desenvolvimento do país beneficiário, há o risco da transferência de conhecimento obsoleto ou de produto em fase de experimentação nos países industrializados, como o caso dos fármacos. Esperando receber tecnologia adequada, os PVDs correm o risco de converter-se em depósito de tecnologias inaproveitáveis dos países industrializados, ou de serem transformados em laboratórios experimentais.

Riscos nesta direção são mostrados em estudos citados por Losego e Arvanitis (2008), que buscam explicar a baixa apropriação de produtos da indústria science oriented nos países periféricos, sublinhando que, nesses, as pesquisas são guiadas pela lógica que decorre do mainstream internacional, em detrimento da utilidade local. Os programas locais se concentram em problemas e objetos do tipo "modelos teóricos", que lhes oferece maior visibilidade científica internacional, como é o caso da "doença de Chagas". Não obstante ter sido elevada à categoria de problema de saúde pública desde os anos 1950, esta doença epidêmica está na lista das negligenciadas pelas indústrias de medicamentos, e é instrumentalizada segundo as lógicas científicas: mesmo a meta expressa no plano nacional sendo prática (conceber vacinas e remédios), as equipes científicas não se afastam da pesquisa fundamental e colaboram muito pouco localmente. Procuram parceiros internacionais e utilizam o parasita apenas como modelo biológico, perseguindo modelos e não soluções.

Tendo em mira a crescente interinstitucionalidade da cooperação, se ela apresenta, por um lado, a vantagem de evitar a morosidade das interações com governos, por outro, apresenta riscos para os países em desenvolvimento. Tais riscos podem conduzir o relacionamento a graves erros jurídicos, ou promover relacionamentos danosos aos interesses dos PVDs. Estes podem se prestar a uma "colonização" por 
parte da instituição estrangeira, e ser utilizados apenas como "posto avançado" de suas pesquisas no exterior, sem terem partilha nos resultados, ou "abrirem as portas" para técnicos estrangeiros mapearem suas capacidades em C\&T e coletarem materiais para pesquisas unilaterais, corroborando as preocupações.

Por outro lado, Soares (1994) mostra dificuldades com os elevados custos da tecnologia, sobretudo aquela de ponta, e das atividades ligadas à $\mathrm{P} \& \mathrm{D}$, implicando medir seu preço em divisas, com a consequente dificuldade dos PVDs em obtê-las. No foco da transferência de tecnologia e dos tipos de contratos e sua regulamentação, o autor chama a atenção para a dificuldade intransponível em conciliar a realidade do mundo dos contratos, regidos por um direito privado, com a realidade de um direito ao desenvolvimento, apoiado no Direito Internacional Público. A temática relaciona-se a direitos ligados às transferências de bens ou de serviços, e mesmo de capitais, que fogem ao controle direto dos Estados envolvidos, pois são direitos de indivíduos ou empresas (entre essas, as multinacionais), fortemente protegidos em nível internacional, com o privilégio que representa um monopólio de propriedade, uso e disponibilidade de bens imateriais, embutidos nos bens ou serviços transferidos. $\mathrm{O}$ autor ressalta, porém, a possibilidade de transferência direta dos próprios direitos da propriedade intelectual, enfatizando que, mesmo nos Estados intervencionistas, está presente a vontade de proteger tais privilégios, sobretudo em nível internacional, pelas atitudes naturalmente protecionistas em relação às $\mathrm{C} \& \mathrm{~T}$ nacionais.

Outros riscos da cooperação em C\&T são apontados por Silva (2007) como a perda de liberdade de ação e criação de dependências, o incremento da complexidade gerencial, riscos políticos, riscos de transferência “indesejada” de tecnologia sensível e ajuda involuntária que venha a criar ou fortalecer futuros competidores. Amorim (1994), por seu turno, complementa que o grande desafio dos PVDs é combinar esforços para aumentar a capacidade própria de absorção e 
geração de tecnologia - para o que são indispensáveis medidas de proteção às suas indústrias - sem perder de vista as oportunidades da cooperação externa.

Grandes dilemas surgem nos processos decisórios da cooperação técnica internacional, em relação aos quais Medeiros (1994) destaca: a) concentração versus dispersão de esforços, sendo vital o estabelecimento de prioridades e programas que contemplem não só como fazer a pesquisa, mas também como utilizar seus resultados; b) definição dos atores que devem intervir na definição de prioridades e programas (uestão complexa pela multiplicidade de atores que participam do processo); c) Estado, sociedade civil e ONGs: que papel devem desempenhar nos processos, e como devem se dar tais relações? d) resultados concretos em curto prazo versus desenvolvimento de capacidade local em médio e longo prazos (este dilema decorre da presença de objetivos de curto, médio e longo prazo nos programas de desenvolvimento no campo da C\&T, os quais competem entre si sob tensão, pelos diferentes horizontes temporais); e, por fim, e) especialização setorial versus enfoques integrados de desenvolvimento: ao se passar de conhecimentos científico-tecnológicos para a aplicação destes na solução de problemas, dificuldades ocorrem porque os primeiros estão organizados em áreas de ciências e disciplinas, enquanto os problemas da vida real não estão circunscritos a tais compartimentos, pois a realidade é mais complexa e multifacetada.

\section{O Brasil diante da Cooperação Internacional em C\&T}

Cervo (1994) argumenta que os objetivos brasileiros da cooperação técnica planejada evoluíram nas últimas décadas do século XX. Acrescenta que, nesse período, enquanto foi possível, procurou-se extrair do PNUD a transferência de C\&T para setores considerados estratégicos e pouco afetados pela cooperação bilateral, já que os paí- 


\section{Cooperação Internacional em Ciência e Tecnologia: Refletindo Conceitos...}

ses prestadores dessa modalidade receavam fazê-lo para não prejudicar seus interesses econômicos e comerciais; a tecnologia de ponta só viria em "pacotes" controlados pelo país de origem, sob uma forma rentável.

Focalizando o Brasil contemporâneo, Troyjo (2003) sugere a afirmação brasileira como fonte de tecnologias adaptáveis às condições dos PVDs, fazendo desta uma alternativa tecnológica a parceiros de estágio socioeconômico equivalente ou inferior em áreas diversas, incluindo meio ambiente, agricultura e saúde. Ressalta a capacidade de o país participar como importante ator da cooperação em C\&T, não só com os países em desenvolvimento, mas também com os industrializados, destacando:

Cabe ao Itamaraty, por meio de sua rede de postos no exterior, estimular atividades que promovam a transferência de conhecimentos, bem como atividades que propiciem a definição de programas que visem à pesquisa científico-tecnológica conjunta, com vistas à inovação, seja de valor econômico industrial, seja de relevância para a solução de problemas sociais que o país ainda experimenta (TROYJO, 2003, p. 124).

Na opinião do autor, visto que o cenário atual é marcado pela prevalência do campo econômico-comercial sobre o político-estratégico, a atuação internacional do Brasil deve buscar conhecimento estratégico pela via do comércio ou da cooperação, que se traduziria no bem-estar da sociedade brasileira e na apreciação de sua estrutura de competitividade na economia mundial, incrementando o espaço que hoje ocupa.

Frente à questão da estrutura temática e institucional da C\&T na diplomacia brasileira, Troyjo (2003) alerta que a mesma precisa sofrer mudanças para se adequar às especificidades dos tipos de cooperação. Lembra que C\&T e cooperação científico-tecnológica não cons- 
tituem um fim em si mesmo, pois operam em determinado setor e compreendem P\&D aplicada às diversas áreas. Assim, a lógica da sua institucionalidade não deve perder de vista a lógica do setor que pretende orientar.

Um complicador importante é que o campo da C\&T apresenta uma multiplicidade de facetas que complexificam esta relação, às quais a política externa de cooperação deve atentar. Isso porque o tema pode ser abordado com relação a "tecnologias sensíveis" ou de uso dual, ou sob uma ótica meramente comercial no que tange à transferência de tecnologia, concernindo à compra e venda de conhecimentos passíveis de aplicação tecnológica e dos equipamentos que dele derivam.

A ênfase atual da política externa brasileira no eixo da tecnologia dirige-se a dois eixos: a) definição de "áreas de ponta" indutoras de transformação tecnológica (como informática, telemática, biotecnologia, novos materiais, tecnologia espacial) e busca da melhoria de tecnologias com impacto social direto (educação, saúde pública, saneamento); e b) incentivo de mudanças estruturais que facilitem a inovação.

Focalizando os principais desafios contemporâneos do governo brasileiro para que a cooperação internacional em C\&T possa trazer benefícios, Krieger e Góes Filho (2005) citam: a) incrementar a cooperação institucional com a participação do Ministério da Ciência e Tecnologia (MCT) e agências, do Ministério das Relações Exteriores (MRE) e da própria Academia Brasileira de Ciências; b) evitar a assimetria entre equipes cooperantes, visando a continuidade dos investimentos; e c) privilegiar a cooperação multilateral, mecanismo mais ágil para formar redes de colaboração entre pesquisadores.

Cabe ainda considerar aqui que, para um país como o Brasil, a atenção à temática científico-tecnológica pode representar uma "janela de oportunidade" para a sua projeção internacional. Ademais, o espaço científico-tecnológico (sobretudo da Sociedade Global de In- 
formação), diferentemente de outros setores da relação entre Estados, está marcado por uma agenda internacional ainda em construção, erigida sobretudo por atividades de cooperação internacional. Vale lembrar a revitalização pela qual passa a cooperação científico-tecnológica, pois países de maior sofisticação nesse campo identificam hoje, em alguns setores, a necessidade de parceiros não tradicionais de razoável equivalência, a exemplo de países emergentes como Brasil, Rússia, China, Índia e África do Sul, o que sinaliza para estes amplas possibilidades e oportunidades.

É mister aqui destacar que promissores exemplos de cooperação internacional em C\&T não tradicional começam a proliferar. Um deles é o Projeto Cyclone- $4^{3}$ que prevê para breve o lançamento de foguete em parceria do Brasil com a Ucrânia, a partir do Centro de Lançamento de Alcântara, no Maranhão. Outro caso é o Programa CBERS (China-Brazil Earth Resources Satellite), acordo de 1988 envolvendo o Instituto Nacional de Pesquisas Espaciais (INPE) e a Academia Chinesa de Tecnologia Espacial (CAST) para construção de satélites avançados de sensoriamento remoto, que hoje se encontra em etapa de revisão dos resultados dos testes elétricos e ambientais do satélite sinobrasileiro CBERS-3. ${ }^{4}$ Dias (2005) sublinha que o Programa Sul-Americano de apoio às atividades de cooperação em C\&T do Brasil com países da América do Sul (PROSUL) é outro exemplo desta natureza, já que o seu objetivo é apoiar atividades de cooperação que contribuam de forma sustentada para o desenvolvimento científico e tecnológico da região.

O programa da Estação Espacial Internacional ${ }^{5}$ (ISS) é mais um exemplo atual da realidade de cooperação em C\&T, ainda que neste caso relativizada, visto o Brasil se integrar com mais quinze países, tendo a agência espacial americana (NASA) como coordenadora. O Brasil foi convidado pelo governo americano para realizar uma parcela da tarefa da NASA, que detém cerca de 50\% do consórcio. Entretanto, a participação do país foi definida na mera categoria de colaborador, enquanto os demais países-membros se configuram na relação como parceiros de cooperação horizontal Norte-Norte. 
Já no foco institucional, merece ser reconhecida a estatal Embrapa, como um notável exemplo de mobilização e oportunização frente à cooperação internacional em C\&T. Criada em 1973, ela vem tecendo uma teia de relações externas profícuas, realizando cooperação com muitas instituições e países, que vêm contribuindo para o elevado nível de desenvolvimento científico e tecnológico do Brasil neste setor. Pesquisa de doutorado em curso analisa a cooperação internacional em C\&T do Centro de Pesquisa Agropecuária do Trópico Semiárido da Embrapa (CPATSA), desde a sua implantação, diante de diversas dimensões desta cooperação, o que inclui aquelas de caráter político e estratégico, bem como aquelas ligadas à C\&T e inovação produzida pela conjugação de esforços, competências e experiências dos atores envolvidos nesses processos. A unidade de análise do estudo é o CPATSA, ou Embrapa Semiárido, cuja posição é estratégica dentro da região do Semiárido Tropical brasileiro, vez que se situa no centro desta. Alguns dos mais recentes dados obtidos constatam acentuado grau de inovação dessas experiências. Entre os muitos parceiros da lista de cooperantes do CPATSA, encontram-se Japão, EUA, Alemanha, França, Reino Unido, Holanda, Argentina, Uruguai e, recentemente, o Sri-Lanka, por meio do seu Departamento de Agricultura (DOA), e a Austrália, por meio da Commonwealth Scientific and Industrial Research Organization (CSIRO), com a qual a cooperação está principalmente voltada para aplicação de técnicas moleculares avançadas em cana-de-açúcar, melhoramento genético e sanidade na área animal, além da utilização de programa de modelagem desenvolvido pela CSIRO que permite a avaliação de sistemas produtivos diversos.

\section{Considerações Finais}

Sabendo-se que a cooperação internacional pode tornar-se elemento importante da estratégia de desenvolvimento tecnológico autônomo de um país, e diante das questões ora discutidas, é imperativa uma 
profunda reflexão sobre a política externa que se deve elaborar e implementar nas modalidades de cooperação científico-tecnológica e técnica para o país. É patente que a dinâmica científico-tecnológica influenciará cada vez mais os caminhos da economia mundial e sua movimentação será refletida em todos os aspectos internacionais, o que engendra um imprescindível tangenciamento da temática científico-tecnológica por toda interface de atuação externa.

Destarte, diante do panorama e reflexões aqui desenvolvidas, não obstante os riscos e desafios a serem enfrentados, fica evidenciado que, para os campos científico e tecnológico, existem "avenidas" de cooperação internacional a serem percorridas. Entretanto, para que esse potencial possa ser bem explorado, devem ser pensadas iniciativas com vistas a um desenvolvimento orientado para as prioridades da maioria e das gerações futuras, respeitando-se o patrimônio cultural dos povos no seu processo de emancipação e alfabetização tecnológica, como sugerido por Bazzo et al. (2003). Para tanto, é impositiva uma interação entre a cooperação internacional e os programas nacionais de desenvolvimento científico e tecnológico, bem como a estruturação democrática de uma política de cooperação internacional no campo de C\&T, com base em uma estratégia bem articulada com parceiros afins, que venha a se concretizar em ações efetivas e sustentáveis. Tal afirmação se conforma não apenas perante as reflexões dos autores, mas também diante das evidências trazidas nas Conferências Nacionais de Ciência, Tecnologia e Inovação, todas elas enfatizando a importância vital da cooperação internacional para o avanço científico das nações. A $4^{\underline{a}}$ Conferência ocorrida em 2010 ressaltou catorze recomendações para o avanço da ciência brasileira: destas, cinco voltadas diretamente para cooperação internacional e as demais tangenciando esta. Um exemplo contundente da determinação do Estado brasileiro na linha de fomentar a cooperação internacional em C\&T é o condicionamento que a Coordenação de Aperfeiçoamento de Pessoal de Nível Superior (Capes) faz hoje, exi- 
gindo a presença de cooperação internacional para melhorar as avaliações dos programas de pós-graduação, mestrado e doutorado.

Assim, visto que a cooperação internacional desempenha um papel de profunda relevância para o desenvolvimento institucional da ciência, como muitos exemplos mostram, a cooperação internacional em C\&T deve ser vista como um instrumento decisivo para fomento da geração autóctone do conhecimento, sendo inconteste que uma política nesta direção deve ser preocupação de qualquer Estado-nação. Ratificando Baiardi e Ribeiro (2011), os benefícios desta cooperação podem ser amplos, com alcance no nível federativo e subfederativo, na medida em que esta fomenta pesquisas que levam ao dinamismo das cadeias produtivas. Ademais, induzindo a produção regional do conhecimento científico-tecnológico, a cooperação internacional em C\&T intensifica a oferta de inovações e com ela as possibilidades de a economia regional internalizar vantagens monopólicas temporárias, inclusive no comércio intranacional.

No caso de países com reduzidos orçamentos públicos e fragilidade nos sistemas nacionais de educação superior e de pesquisa, como a grande maioria dos países africanos, uma medida urgente em políticas públicas deveria ser a busca de apoio da cooperação internacional, visando preservar e reforçar suas capacidades científicas, sem o que tais objetivos se tornariam dificultosos, senão inalcançáveis, em um primeiro momento. A cooperação internacional em C\&T pode ainda dar suporte e criar centros de excelência sobre os quais poderiam se apoiar os sistemas nacionais de pesquisa.

Cabe lembrar que a transferência de tecnologia para promover o desenvolvimento sustentável é uma das questões centrais para a concepção e apropriação de "tecnologias verdes" reclamadas pelo planeta. A importância da tecnologia para um novo paradigma tecno-industrial-ambiental exige o pleno aproveitamento de conhecimentos acumulados, incluindo os decorrentes de avanços tecnológicos mais 
recentes, para o que a cooperação internacional em C\&T deve ter um papel fundamental. Não é difícil constatar que este tipo de cooperação é o instrumento que pode conduzir o processo de governança mundial para a sustentabilidade ambiental do planeta. Os desafios de operacionalizá-lo diante das dificuldades inerentes a um processo multidisciplinar e pluricultural são incontestavelmente extensos. Não obstante a forma "anárquica" do sistema internacional, não detentor de autoridade central, um futuro alvissareiro pode ser descortinado com a promoção de formas benéficas de cooperação internacional se os governos buscarem um caminho mais bem coordenado, com apoio de pesquisadores e acadêmicos nesse processo, corroborando Axelrod e Keohane (1985).

Finalizando, sendo a cooperação internacional um instrumento da política externa de um país, e aquela voltada para a C\&T uma de suas modalidades, é essencial que os governantes atentem para que todas as políticas transversais ao tema estejam alinhadas e convergentes. Só assim será possível potencializar essa cooperação de modo a que venha refletir a realidade da sociedade, seus anseios e necessidades, em consonância com o seu processo histórico-cultural, visto que, como sugerem Baiardi e Ribeiro (2011), nenhum Estado e sociedade modernos podem hoje prescindir da cooperação internacional em ciência e tecnologia.

\section{Notas}

1. Esta e as demais citações de originais em língua estrangeira foram livremente traduzidas para este artigo.

2. Inúmeros textos de história da ciência tratam serendipity como insight essencial para certas descobertas. 
3. Veiculação no site do programa: <http://www.alcantaracyclonespace. com/>. Acesso em: 17 set. 2013.

4. Notícia do Instituto Nacional de Pesquisas Espaciais (INPE). Disponível em: <http://www.cbers.inpe.br/>. Acesso em: 17 set. 2013.

5. Notícia veiculada pela NASA em: <http://www.nasa.gov/mission_pages/ station/main/index.html>. Acesso em: 17 set. 2013.

\section{Referências Bibliográficas}

ALBERGONI, G. Excedente. In: ROMANO, R. (Org.). Produção, distribuição, excedente. Lisboa: Enciclopédia Einaudi, 1995.

AMORIM, C. L. N. Perspectivas da cooperação internacional. In: MARCOVITCH, J. (Org.). Cooperação internacional: estratégia e gestão. São Paulo: Edusp, 1994.

AXELROD, R.; KEOHANE, R. O. Achieving Cooperation under Anarchy: Strategies and Institutions. World Politic, v. 38, n. 1, p. 226-254, Oct. 1985. Disponível em: <http://www.jstor.org/stable/2010357>. Acesso em: 21 jun. 2012.

AYLLÓN, B. O sistema internacional de cooperação ao desenvolvimento e seu estudo nas Relações Internacionais: a evolução histórica e as dimensões teóricas. Revista de Economia e Relações Internacionais, v. 5, n. 8, 2006.

BACON, F. Advancement of Learning, First Book e Novum Organum, First Book. Chicago: Encyclopaedia Brittanica-Great Books of the Western World, 1952.

BAIARDI, A. Sociedade e Estado no apoio à ciência e à tecnologia. São Paulo: Hucitec, 1997.

. A dimensão da municipalidade da C\&T e as possibilidades de uma gestão integrada. Jornal da Ciência, p. 1-5, 24 nov. 2004. 
Cooperação Internacional em Ciência e Tecnologia: Refletindo Conceitos...

; BASTO, C. A busca pela terceirização em P \& D: o caso do CETENE no nordeste do Brasil. In: Anais do XV Congresso da Associação Latino Ibero-Americana de Gestão de Tecnologia, ALTEC. Porto: ALTEC, 2013.

BAIARDI, A.; RIBEIRO, M. C. M. A cooperação internacional norte-sul na ciência e na tecnologia: gênese e evolução. Caderno CRH, v. 24, n. 63, Dec. 2011. Disponível em: <http://www.scielo.br/scielo.php?script=sci_arttext\& pid $=$ S0103-49792011000300009\&lng=en\&nrm=iso $>$. Acesso em: 22 jul. 2012.

BAZZO, W. A.; VON LINSEGEN, I.; PEREIRA, L. T. do V. Introdução aos estudos CTS (Ciência, Tecnologia e Sociedade). Madri: Organización de Estados Iberoamericanos, 2003.

CASTELLS, M. A economia informacional, a nova divisão internacional do trabalho e o projeto socialista. Caderno CRH, n. 17, p. 5-34, 1992.

CERVO, A. L. Socializando o desenvolvimento: uma história da cooperação técnica internacional do Brasil. Revista Brasileira de Política Internacional, v. 37, n. 1, p. 37-63, 1994.

DELORS, J. Crescita, competività, occupazione. Il libro bianco delia comissione delle Comunità Europee. Milão: Lisa Giatore, 1994.

DIAS, L. de C. Programa sul-americano de apoio às atividades de cooperação em ciencia e tecnologia do Brasil com países da América do Sul (PROSUL). Seminários temáticos para a $3^{\mathrm{a}}$ Conferência Nacional de C,T\&I. Parcerias Estratégicas, n. 20, jun. 2005. Disponível em: <http://cncti3.cgee.org.br/Documentos/Seminariosartigos/Presencainternacional/DrLindolphodeCarvalhoDias. pdf>. Acesso em: $1^{\circ}$ jul. 2012.

DOSI, G.; FREEMAN, C.; NELSON, R.; SILVERBERG, G.; SOETE, L. Technical change and economic theory. Londres: Pinter Publishers, 1990.

EPSTEIN, S. R.; PRAK, M. Guilds, innovation and the European economy, 1400-1800. Cambridge: Cambridge University Press, 2009.

FABIETTI, U. Pastorícia. In: ROMANO, R. (Org.). Produção, distribuição, excedente. Lisboa: Enciclopédia Einaudi, 1995.

FEYERABEND, P. Contra o método. Rio de Janeiro: Francisco Alves, 1989. 
GAILLARD, J. La naissance difficile des communautés scientifiques. In: SALOMON, J. J.; SAGASTI, F.; SACHS-JEANTET, C. La quête incertaine, science, technologie, development. Paris: Economica, 1994.

GODELIER, M. Caça/recolecção In: ROMANO, R. (Org.). Produção, distribuição, excedente. Lisboa: Enciclopédia Einaudi, 1995.

HESSEN, J. Teoria do conhecimento. São Paulo: Martins Fontes, 2000.

KRIEGER, E. M.; GÓES FILHO, P. A importância da cooperação internacional para o desenvolvimento da ciencia brasileira. Revista Parcerias Estratégicas, n. 20, jun. 2005.

KUHN, T. S. Estrutura das revoluções científicas. São Paulo: Editora Perspectiva, 2010.

LAFER, C. Política externa brasileira: reflexão e ação. In: MARCOVITCH, J. (Org.). Cooperação internacional: estratégia e gestão. São Paulo: Edusp, 1994.

LANDES, D. S. O Prometeu desacorrentado: transformação tecnológica e desenvolvimento industrial na Europa Ocidental, desde 1750 até nossa época. Rio de Janeiro: Nova Fronteira, 1994.

A riqueza e a pobreza das nações: por que algumas são tão ricas e outras tão pobres. Rio de Janeiro: Editora Campus, 1998.

LATOUR, B. Ciência em ação - como seguir cientistas e engenheiros sociedade afora. São Paulo: Unesp, 1997.

LOSEGO, P.; ARVANITIS, R. La Science dans les Pays non Hégémoniques. S.A.C. Revue d'Anthropologie des Connaissances, v. 2, n. 3, p. 334-342, 2008. Disponível em: $<$ http://www.cairn.info/revue-anthropologie-des-connaissances-2008-3-page-334.htm>. Acesso em: 5 ago. 2012.

MEDEIROS, A. P. C. As organizações internacionais e a cooperação técnica. In: MARCOVITCH, J. (Org.). Cooperação internacional: estratégia e gestão. São Paulo: Edusp, 1994.

MERTON, R. K. The sociology of science: theoretical and empirical investigations. Chicago: The University of Chicago Press, 2008.

MILL, J. S. Sistema de lógica dedutiva e indutiva e outros textos. São Paulo: Abril Cultural, 1978. [Coleção Os Pensadores]. 
ORTEGA Y GASSET. Obras completas. Madri: Santilla-Fundación Ortega y Gasset, 2005.

PIGGOTT, S. A Europa antiga. Lisboa: Fundação Calouste Gulbenkian, [s.d.].

POPPER, K. Lo scopo della scienza. Roma: Armando Editore, 2000.

REUTER, P. Institutions internationales. Paris: Presses Universitaires de France, 1955.

RIBEIRO, M. C. M. Globalização e novos atores: a paradiplomacia das cidades brasileiras. Salvador: EDUFBA, 2009.

ROSENBERG, N. Por dentro da caixa-preta, tecnologia e economia. Campinas: Editora Unicamp, 2006.

SANAHUJA, J. A. y Gómez; GALÁN, M. El sistema internacional de la cooperación al desarrollo. Madri: CIDEAL, 1999.

SCHMOOKLER, J. Invention and economic growth. Cambridge: Harvard University Press, 1966.

SHAPIN, S. The scientific life. Chicago: The University of Chicago Press, 2008.

SILVA, D. H. da. Cooperação internacional em ciência e tecnologia: oportunidades e riscos. Revista Brasileira de Política Internacional, v. 50, n. 1, Jun. 2007. Disponível em: <http://www.scielo.br/scielo.php?script=sci_arttext\& pid=S0034-73292007000100001\&lng=en\&nrm=iso $>$. Acesso em: $1^{\circ}$ jul. 2012.

SOARES, C. F. A cooperação técnica internacional. In: MARCOVITCH, J. (Org). Cooperação internacional: estratégia e gestão. São Paulo: Edusp, 1994.

STOKES, D. E. O quadrante de Pasteur: a ciência básica e a inovação tecnológica. Campinas: Editora Unicamp, 2005.

TROYJO, M. P. Tecnologia \& diplomacia: desafios da cooperação internacional no campo científico-tecnológico. São Paulo: Aduaneiras, 2003.

THUILLIER, P. De Arquimedes a Einstein. Rio de Janeiro: Jorge Zahar Editor, 1994. 
Maria Clotilde Meirelles Ribeiro e

Amilcar Baiardi

VIEIRA, A.; BAIARDI, A.; BAIARDI, D. C. História da ciência, abordagem introdutória. Cachoeira: UFRB Mestrado em Ciências Sociais, 2010.

\section{Resumo}

\section{Cooperação Internacional em Ciência e Tecnologia: Refletindo Conceitos e Questões Contemporâneas}

$\mathrm{O}$ artigo discute a cooperação internacional para o desenvolvimento no eixo da Ciência e Tecnologia (C\&T), analisando questões cruciais contemporâneas e questões brasileiras específicas. Partindo de contribuições de relevantes autores, o trabalho focaliza os conceitos centrais de ciência, tecnologia e cooperação internacional em C\&T, com distintas visões de especialistas em diferentes períodos. Na sequência, aborda tipologias da cooperação internacional, introduzindo uma reflexão sobre a técnica e a natureza humana, e sobre distinções entre "técnica" e "tecnologia", bem como especificidades dos vetores da cooperação científico-tecnológica e da cooperação técnica. Prosseguindo, o artigo traz um breve histórico da trajetória da cooperação internacional em C\&T, notadamente nos momentos demarcados pela Guerra Fria, aporta exemplos concretos e debate dilemas, oportunidades, riscos e desafios, bem como a realidade do Brasil diante deste instrumento da política externa dos governos.

Palavras-chave: Ciência - Tecnologia - Cooperação - Política Externa

\section{Abstract}

\section{International Cooperation in Science and Technology: Reflecting about Concepts and Contemporary Issues}

The article discusses international cooperation in science and technology (S\&T), analyzing its crucial contemporary issues, as well as Brazilian 


\section{Cooperação Internacional em Ciência e Tecnologia: Refletindo Conceitos...}

specific issues. It presents several contributions from relevant scholars and focuses on the concepts of science, technology and international cooperation, its main terminologies and several visions of specialists in different periods. Furthermore, it brings international cooperation typologies and introduces a reflection on technique and the human nature, emphasizing features that distinguish "technique" of "technology" and exploring the vectors of the scientific-technological cooperation and technical cooperation. The paper provides a short historical overview of international cooperation, notably in the moments marked by the Cold War as a dividing line, and by providing concrete examples, it discusses the key issues of international cooperation in S\&T in the contemporary world, as well as the reality of Brazil towards this tool of governmental foreign policy.

Keywords: Science - Technology - Cooperation - Foreign Policy 